\title{
Emotional Labor Strategy of Hotel Frontline Employees: The Antecedents and Consequences
}

\author{
Xiaofen Liu \\ School of Management, Jinan University, Guangzhou, China \\ Email: 13973817830@163.com
}

How to cite this paper: Liu, X.F. (2017) Emotional Labor Strategy of Hotel Frontline Employees: The Antecedents and Consequences. Journal of Service Science and Management, 10, 425-436. https://doi.org/10.4236/jssm.2017.105034

Received: September 30, 2017

Accepted: October 23, 2017

Published: October 26, 2017

Copyright $\odot 2017$ by author and Scientific Research Publishing Inc. This work is licensed under the Creative Commons Attribution International License (CC BY 4.0).

http://creativecommons.org/licenses/by/4.0/

\section{cc) (i) Open Access}

\begin{abstract}
This study focused on frontline employees from 4 hotels in a certain hotel group, researching with a questionnaire survey. It examined the relationship between hotel frontline employees' emotional labor strategy selection and its reluctant variables (antecedents and consequences). Results indicate that the frequency of using deep acting is higher than surface acting among hotel frontline employees. Surface acting shows significant difference in gender, deep acting with a significant difference in age and education level; positive affect and intrinsic regulation have relatively positive correlation with deep acting. Surface acting is positively related to emotional exhaustion and turnover intention. Furthermore, frontline employees in hotels have presented job burnout and obvious turnover intention.
\end{abstract}

\section{Keywords}

Hotel Frontline Employee, Emotional Labor Strategy, Job Burnout, Turnover Intention

\section{Introduction}

Emotional labor emerges at the process of emotional play management as employees serve customers during interpersonal interaction. Job duty would never be restricted to apparent work, and managing their own emotion is also necessary, which caused emotional labor [1]. Under the hospitality background, study of emotional labor around hotel staff has become a significant branch of EI field [2]. In service process, customers may form corresponding quality perception through emotive coping played by hotel frontline employee [3] [4] [5]. For a service-oriented corporation, emotional performance of its employees has an effect on outcomes including retention and satisfaction of customers, employees' emotional exhaustion, turnover intention, etc. [6] [7] [8]. Now, most human re- 
source operators in hotels begin to notice emotional labor phenomenon, hoping to take effective measures to control exhaustion through managing employees' emotion. Thus, examining emotional labor strategy selection and factors of antecedents and consequences would be valuable for application.

\section{Literature Review}

\subsection{Emotional Labor Strategy}

According to comparing previous perspectives of emotional labor, two common regulation strategies are pointed out, that is surface acting and deep acting. Individuals would choose surface acting to constrain their true affection, then fake to express standard emotion without identifying emotional play rules of organization by heart, which belongs to a hiding behavior, not consistent with psychological feelings. That is definition of surface acting. The next one is engaging in deep acting through reappraisal in advance, this strategy aims to accept emotional play rules that organization advocates. Besides, a third strategy generates, under the situation individual feelings conform to expression rules spontaneously, a kind of emotional expression would not expend psychological regulation, that called expression of naturally felt emotion [1]. Due to the special feature of needing a little effort to regulate, expression of naturally felt emotion is out of scope discussed in this study.

\subsection{Antecedents of Emotional Labor}

In the research on antecedent-focused emotional labor, mostly taking individual difference into account firstly, the researchers find individual traits have an effect on this selection of emotional labor strategy [2] [9]. Display rules for organization cannot produce the same confined effectiveness in terms of employees, because personality largely determines its own cognition and behavior [5]. The individual factors include demographic characteristics, psychological capital, emotional intelligence, affection, traits etc. Individual characteristics have a certain difference in selection of emotional labor strategy [10] [11] [12].

Personality traits, specifically positive affections and negative ones, may predict surface acting and deep acting [6] [7]. Grant (2013) demonstrated, extraversion in big five personality negatively related with surface acting, and positively related with deep acting [13]. Sohn et al. (2014) sampled with employees from tourism industry, agreeableness and openness were found to influence significantly on surface acting. Meanwhile, extraversion, agreeableness, conscientiousness, and openness had a positive influence on deep acting [14]. Using HEXACO theory examined the relationship between personality and emotional labor for tourism service providers, conclusions implicated three factors including honesty-humility, agreeableness, and openness influenced surface acting significantly. Extraversion, agreeableness, conscientiousness and openness were evidenced to have a positive effect on deep acting [15]. Tourism employees' emotional intelligence played an important role in emotional labor strategy 
through motivation mediates. Extrinsic motivation effected on surface acting, at the same extrinsic motivation could change into intrinsic motivation to influence deep acting [16] [17]. Therefore, this study depends on previous studies about emotional labor antecedents as a reference: examining hotel frontline employees' individual character, personality trait, work motivation and emotional labor strategy selection [18].

\subsection{Consequences of Emotional Labor}

Relevant consequent variables studies mainly integrated effects on display emotion of employees. For individuals, what emotional labor would have a certain impact is negative, including self-alienation, depersonalization, work stress, job burnout etc [19]. Long-term emotional labor for service employees may easily cause the outcome of emotional exhaustion [20], with a negative effect on work attitude, satisfaction and burnout [21]. Zhao Xu (2013) chose frontline service employees of 4 hotels in Chang Chun as a sample, then examined the relationship of emotional labor, burnout and turnover intention: Surface acting and deep acting have a remarked impact on three dimensions of burnout, which is respectively positive and negative on this consequence [8]. Due to the mediation of burnout, emotional labor produced an effect on turnover intention. A comparison study for frontline employees in airlines gave out with a long-term and short-term observation, whose conclusion was employees' emotional labor negatively influenced their emotional exhaustion and reduced staying intention for a long term.

A meta-analytic study indicated that deep acting significantly increased customer satisfaction and employees' personal accomplishment. Moreover, surface acting relatively promoted depersonalization and exhaustion, inversely decreased job satisfaction [22]. Another meta-analytic study proved deep acting could predict to raise job satisfaction and performance. Surface acting also effected on the increase of stress and decrease of job satisfaction [23]. As the results of two meta-analytic studies above, it was found that variables (including emotional exhaustion, job satisfaction, stress, performance) have a convinced interpretation as emotional labor consequences. According to practical situation in hotel and analysis of consequences above, this study selects job burnout (emotional exhaustion, depersonalization, reduces personal accomplishment) and turnover intention as consequences of emotional labor, discuss what effects emotional labor strategy for hotel frontline employees make on the two variables.

\section{Study Design}

\subsection{Sample and Procedure}

The setting for the study was four hotels of a certain hotel group located in China. The respondent sample was drawn from frontline employees who worked in the hotels and had direct interactions with customers. A total of 223 hotel fron- 
tline employees participated in the present questionnaires. 202 usable responses were returned (90.58\%). Of the valid sample, $35.2 \%$ were male, and $64.8 \%$ were female. The age of respondents intensively ranged from $20-25$. Over a half (50.8\%) possessed a university degree, with the rest (49.2\%) completing their education at secondary school level, even below. The respondents came from the three departments of hotels (lobby: 50.5\%, restaurant: $31.2 \%$, recreation: 17.8\%). $67.7 \%$ of employees in the survey had hotel work experience over one year, and $32.3 \%$ experienced less than one year in the hotels.

\subsection{Measures}

Because of the limitation of foreign scales, this study assigned professors in tourism management to complete a two-way translation. For ensuring the validity of scales, it gave further revise and improvement to translated sentences, and next talked about the evaluation of scale items with professors from service research area, A pre-test was necessary to repair wording and expression for some items. Through the process above for promising the reliability and validity of questionnaires, the final scale design formed. All of the scales used in the study were quoted from advanced international journals. Additionally, having been repeatedly tested in multiple cultural context guaranteed context validity of scales. Every item was rated on a Likert 5 -point scale $(1=$ strongly disagree, 5 = strongly disagree).

\subsubsection{Emotional Labor}

11 items two-dimensional emotional labor scale [2] was used for the purpose of measuring hotel frontline employees' emotional labor strategy. In this investigation, item 1 to 7 measured surface acting strategy, items 8 to 11 measured deep acting strategy. The applicable Cronbach alpha coefficient was 0.815 .

\subsubsection{Big Five Personality}

Personality traits measure that has been used in the present study was consistent with Watson, Clark \& Tellegen's (1998) The PANAS Scales [24]. Employees were asked working feelings and emotion acquired within a month, aiming to reveal the relationship between affect (positive affect and negative affect) and emotional labor strategy. The scale described PA and NA with ten categories of emotion feelings. The Cronbach alpha coefficient was 0.799 .

\subsubsection{Work Motivation}

The motivation at work was accessed with the scale designed by Gagne (2010) [25]. Four dimensions constituted the work motivation scale, consisting of intrinsic regulation, identified regulation, interjected regulation and external regulation. Every dimension had been measured by three items. The applicable Cronbach alpha coefficient for 12-item was 0.868 .

\subsubsection{Job Burnout}

Maslach Burnout Inventory Human Service Survey [26] was classically cited for 
measuring employees' job burnout. The scale was divided into three dimensions (emotional exhaustion, depersonalization and reduced personal accomplishment), with every dimension measured by three items. The applicable Cronbach alpha coefficient was 0.903 .

\subsubsection{Turnover Intention}

Turnover intention was operated via four items, just sample as "I should find another job soon", "I often want to resign", "I will quit this job sometime next year", "It' s not difficult for me to quit this job", from using Babakus et al. [27], whose Cronbach alpha coefficient in this study was 0.876 .

\section{Data statistical Analysis}

\subsection{Descriptive Statistical Analysis}

For penetrating into emotional labor situation of hotel frontline employees, this study analyzed all the measured variables with descriptive statistics (Table 1). Results indicated: frontline employees in hotels did less surface acting $(M=2.60)$ than deep acting $(\mathrm{M}=3.05)$. That is, deep acting strategy is preferred to use in the two kinds of labor.

In terms of motivation at work, external regulation was the lowest, which was below a middle value 3 in these four dimensions of work motivation $\left(M_{\text {intrinsic regu- }}\right.$ lation $\left.=3.70, \mathrm{M}_{\text {interjected regulation }}=3.47, \mathrm{M}_{\text {identified regulation }}=3.38, \mathrm{M}_{\text {external regulation }}=2.76\right)$. It

Table 1. Descriptive statistics in scales.

\begin{tabular}{|c|c|c|c|c|}
\hline Scale & Dimension & Sample & Mean & SD \\
\hline \multirow{3}{*}{$\begin{array}{c}\text { Emotional Labor } \\
\text { Strategy }\end{array}$} & Surface Acting & 202 & 2.60 & 1.09 \\
\hline & Deep Acting & 202 & 3.05 & 1.039 \\
\hline & Intrinsic Regulation & 202 & 3.7 & 0.86 \\
\hline \multirow{3}{*}{ Work Motivation } & Identified Regulation & 202 & 3.38 & 1.03 \\
\hline & Interjected Regulation & 202 & 3.47 & 1.03 \\
\hline & External Regulation & 202 & 2.76 & 1.1 \\
\hline \multirow{3}{*}{$\begin{array}{l}\text { Personality Cha- } \\
\text { racteristics }\end{array}$} & Positive Affect & 202 & 3.21 & 1.03 \\
\hline & Negative Affect & 202 & 2.11 & 0.96 \\
\hline & Emotional Exhaustion & 202 & 2.48 & 0.95 \\
\hline \multirow[t]{4}{*}{ Job Burnout } & Depersonalization & 202 & 2.17 & 0.9 \\
\hline & Reduced Personal Accomplishment & 202 & 2.49 & 0.96 \\
\hline & Turnover Intention General Comment & 202 & 2.61 & 1 \\
\hline & I should find another job soon & 202 & 2.60 & 1.020 \\
\hline \multirow{3}{*}{$\begin{array}{l}\text { Turnover Inten- } \\
\text { tion }\end{array}$} & I often want to resign & 202 & 2.35 & 0.943 \\
\hline & I will quit this job sometimes next year & 202 & 2.67 & 1.021 \\
\hline & It's not difficult for me to quit the job & 202 & 2.82 & 1.033 \\
\hline
\end{tabular}


demonstrates work motivation mainly depend on another three self-regulation ways, instead of external regulation. That is to say, work motivation originates from happiness and interest for work, This kind of employees cares what effect on their fame if encountering work failure, even check whose work values are consistent with self-values. In the personality characteristics aspect, positive affect $(M=3.21)$ was more abundant that negative affect $(M=2.11)$, which illustrated most frontline employees' emotion was positive. As for job burnout, overall score was general, the most noticeable dimension was depersonalization with an average of 2.17only. Emotional exhaustion and reduced personal accomplishment were relatively 2.48 and 2.49; Turnover intention $(\mathrm{M}=2.61)$ was beyond its own average (2.5). Consequently, hotel frontline employees have a certain turnover intention.

\subsection{Variance Analysis}

T-test and one-way ANOVA were adopted for analyzing differences on demographic characteristics. Further study results about emotional labor of hotel frontline employees were following:

\subsubsection{Young Employees' Deep Acting Strategy Level Is Significantly Lower than the Elders'}

Employees' age did not have much effect on surface acting, nevertheless, deep acting had an significant difference on age $(\mathrm{F}=2.769, \mathrm{P}=0.029<0.05)$. Next a result of multiple comparison analysis indicated, 18 - 19 year-old employees used less deep acting strategy than employees in the other three age groups (20 22, 23 - 25, 26 - 30). Generally, 18 - 19 year-old employees mostly come to the workplace for a moment, which of them have poor ability in recognizing their own or others' emotion, and need to improve the ability of psychological regulation. Therefore, employees just entering the workplace play a weak role in deep acting.

\subsubsection{Surface Acting Strategy Selection Have a Significant Difference in Gender}

A t-test with the sample of male and female employees was applied in this emotional labor study. There was not any remarkable difference of deep acting in employees' gender. But a significant difference of surface acting existed in gender $(T=0.020, P=0.006<0.01)$. A particular comparison analysis convinced, the level of surface acting strategy of male employees were higher than female employees' $\left(\mathrm{M}_{\text {male }}=2.8739, \mathrm{M}_{\text {female }}=2.4777\right)$. Compared to female employees, males are more willing to meet emotional needs through regulating their surface acting emotion. Taking in emotional labor is advantaged for female, because they think more carefully than males, and rich in emotion.

\subsubsection{High Degree Employees Use More Deep Acting Strategy Frequently than Low Educational Employees \\ Variance analysis of emotional labor with different education levels, showed}


education had a significant difference in deep acting $(\mathrm{F}=5.293, \mathrm{P}=0.002<$ 0.01 ), but no distinct difference in surface acting. Another multiple comparison analysis attested, the deep acting strategy level of college degree employees were significantly higher than employees of secondary school education. In addition, bachelor degree employees presented higher deep acting level than employees of secondary school education, even below. To sum up, employees with higher diplomas often do better in deep acting, who take measure to regulate emotion with mental processing, so as to adapt to new conditions especially when facing emotional labor.

\subsubsection{Neither Working Condition Nor Experience Has Any Significant Effect on the Selection of Emotional Labor Strategy}

As expected, there was not significant difference of departments in two kinds of emotional labor strategies. Comparatively, the deep acting strategy level of front-office was the highest $(M=3.1692)$. Recreation was the lowest in two kinds of acting strategies $\left(\mathrm{M}_{\text {surface acting }}=2.5592, \mathrm{M}_{\text {deep acting }}=2.8347\right)$.

Work experience and emotional labor were also analyzed by variance analysis. It revealed that length of employed time was not significantly correlated with the selection of emotional labor strategy. Employees with over 36 months of working experience performed highest in surface and deep acting $\left(\mathrm{M}_{\text {surface acting }}=\right.$ $2.9732, \mathrm{M}_{\text {deep acting }}=3.2813$ ). Meanwhile, the second highest was employees within three months $\left(\mathrm{M}_{\text {surface acting }}=2.7027, \mathrm{M}_{\text {deepacting }}=3.2297\right)$.

More specifically, variance analysis with hotel industry working experience and emotional labor strategy carried out. Working experience of hotel industry had no remarked difference on emotional labor. Employees with over 5 years of industry work experience $\left(\mathrm{M}_{\text {surface acting }}=2.3626, \mathrm{M}_{\text {deep acting }}=2.6923\right)$ played in emotional labor less frequently than other groups. This type of frontline employees mainly consisted of professional women whose life cycle in family may be in the extended period. Job involvement depended on self-selection to slope on their family. Emotional labor frequency of employees within 3 months of industry work experience $\left(\mathrm{M}_{\text {surface acting }}=2.6891, \mathrm{M}_{\text {deep acting }}=3.2206\right)$ was over upon average level $\left(\mathrm{M}_{\text {surface acting }}=2.5916, \mathrm{M}_{\text {deep acting }}=3.0380\right)$. Generally, the first three months as entering the hotel industry belong to culture acceptance period. Employees would participate in organizational and systematic training about enterprise culture and service conception, that causes new employees' positive emotion more obvious.

\subsection{Correlation Analysis}

Data was run by correlation analysis, in order to explore interact relation of variables (Table 2).

\subsubsection{Employees with More Positive Affect Tend to Deep Acting}

For hotel frontline employees, positive affect had a positive correlation with deep acting significantly $(\mathrm{r}=0.240, \mathrm{p}<0.01)$, and a negative correlation with surface 
Table 2. Correlation analysis.

\begin{tabular}{|c|c|c|c|c|c|c|c|c|c|c|c|c|}
\hline Variables & 1 & 2 & 3 & 4 & 5 & 6 & 7 & 8 & 9 & 10 & 11 & 12 \\
\hline 1. Surface Acting & 1 & & & & & & & & & & & \\
\hline 2. Deep Acting & $0.376^{* *}$ & 1 & & & & & & & & & & \\
\hline 3. Intrinsic Regulation & -0.079 & $0.141^{*}$ & 1 & & & & & & & & & \\
\hline 4. Identified Regulation & -0.087 & 0.088 & $0.597^{* *}$ & 1 & & & & & & & & \\
\hline 5. Interjected Regulation & -0.084 & 0.112 & $0.506^{* *}$ & $0.512^{\star *}$ & 1 & & & & & & & \\
\hline 6. External Regulation & 0.014 & 0.060 & $0.376^{* *}$ & $0.425^{\star *}$ & $0.345^{\star *}$ & 1 & & & & & & \\
\hline 7. Emotional Exhaustion & $0.211^{* *}$ & 0.023 & $-0.280^{\star *}$ & $-0.273^{\star *}$ & $-0.178^{*}$ & -0.090 & 1 & & & & & \\
\hline 8. Depersonalization & 0.118 & -0.057 & $-0.191^{\star *}$ & -0.121 & $-0.217^{\star *}$ & -0.002 & $0.750^{* *}$ & 1 & & & & \\
\hline $\begin{array}{l}\text { 9Reduced Personal } \\
\text { Accomplishment }\end{array}$ & -0.051 & -0.012 & -0.119 & -0.105 & -0.084 & 0.073 & $0.622^{* *}$ & $0.745^{\star *}$ & 1 & & & \\
\hline 10. Turnover Intention & $0.152^{\star}$ & 0.015 & $-0.419^{\star \star}$ & $-0.406^{\star *}$ & $-0.266^{\star *}$ & $-0.165^{\star}$ & $0.533^{\star *}$ & $0.445^{\star *}$ & $0.426^{\star *}$ & 1 & & \\
\hline 11. Positive Affect & -0.087 & $0.240^{* *}$ & $0.476^{* *}$ & $0.434^{* *}$ & $0.362^{* *}$ & 0.134 & $-0.201^{\star *}$ & -0.096 & 0.011 & $-0.373^{\star *}$ & 1 & \\
\hline 12. Negative Affect & 0.138 & 0.036 & -0.080 & -0.051 & -0.112 & 0.053 & $0.418^{* *}$ & $0.421^{\star *}$ & $0.430^{* *}$ & $0.382^{\star *}$ & -0.026 & 1 \\
\hline
\end{tabular}

${ }^{*} \mathrm{p}<0.05,{ }^{* *} \mathrm{p}<0.01$.

acting but not reaching significance. Emotional labor (surface and deep acting) was not markedly related with negative affection. The study results also showed, positive affected employees preferred to use deep acting strategy, and this type of employees objectively adjusted feelings to reduce negative emotion caused by emotional conflict, simultaneously kept fit in work conditions under the necessity of service needs. Diefendorff (2005) thought extraversion and neuroticism had a strong connect with positive and negative affections [2]. Employees full of more extraversion grasp higher emotional labor skills, who can recognize others' emotion change quickly, then express their own emotion in multiple ways.

\subsubsection{Deep Acting Strategy Is Favored by Employees with Intrinsic Regulation of Work Motivation}

Intrinsic regulation motivation was positively correlated with deep acting $(\mathrm{r}=$ $0.141, \mathrm{p}<0.01$ ). Work motivation was not related with surface acting significantly. It instructed that the more interested employees were in the work to gain happiness from it , the more desirable that they are to use deep strategy. Affected by work interest, employees may actively seek for solutions to deal with emergence of service problems. As is expressed to emotional labor, employees prefer to regulate intrinsically for understanding rules of work emotion, and then service more with deep acting.

\subsubsection{Continual Surface Acting Probably Results in More Emotional Exhaustion and Turnover Intention}

Surface acting had a significant positive correlation with emotional exhaustion ( $\mathrm{r}$ 
$=0.211, \mathrm{p}<0.01)$, but a non significant relation with other two dimensions of job burnout. The more frequently employees use surface acting strategy to service for customers, the more conflict they will have in their hearts. That causes loss of affect and weakness of communication. Finally, emotional labor of hotel frontline employees promotes job burnout as a mediation of emotional exhaustion.

Through the correlation analysis of two variables (emotional labor and turnover intention), surface acting strategy had a significant positive correlation with turnover intention $(r=0.152, \mathrm{p}<0.05)$. There was not a significant correlation between deep acting and turnover intention, which testified surface actors would be more probably to have higher turnover intention.

Furthermore, job burnout $\left(\mathrm{r}_{\text {emotional exhaustion }}=0.533, \mathrm{r}_{\text {depersonalization }}=0.445, \mathrm{r}_{\text {reduced }}\right.$ personal accomplishment $=0.426$ ) presented a significant positive correlation with turnover. For hotel frontline employees, the higher employees have job burnout, the sharper corporations turnover intention is. Emotional exhaustion, depersonalization, and reduces personal accomplishment all can lead to producing of job burnout, ultimately employees' burnout promotes the rising of turnover intention. In the service process of hotel frontline employees, more frequent surface acting strategy would increase the possibility in losing affect, especially passion for work.

\section{Conclusions and Implications}

\subsection{Conclusions}

\subsubsection{Hotel Frontline Employees Tend to Deep Acting More Frequently than Surface Acting}

Hotel frontline employees prefer to use deep acting strategy, which indicates their emotional labor perceptions are consistent with hotel-made performance principles. Most frontline employees can stimulate positive emotions or control negative ones through mental processing.

\subsubsection{Surface Acting Has Significantly Differences in Gender, Positively Related with Emotion Exhaustion and Turnover Intention}

Gender of individual factors present significant differences in surface acting; in detail, male employees will be more willing to use surface acting strategy to meet emotional demand in the face-to-face service process. Other individual factors show no remarkable difference in surface acting. Surface acting is markedly correlated with emotional exhaustion and turnover intention, but not correlated with motivation and personality.

\subsubsection{Deep Acting Has Significantly Differences Both in Age and Education Aspect, While Positively Related with Positive Affect and Intrinsic Regulation}

Young employees with deep acting strategy perform less frequently than other age distribution. High degree employees tend to use deep acting strategy more frequently. Positive affect is correlated with deep acting; additionally intrinsic 
regulation of motivation at work is correlated with deep acting.

\subsubsection{Job Burnout Is Existing in Hotel Frontline Employees, Turnover Intention Is Also Obvious}

There is a certain job burnout among hotel frontline employees, who feel exhausted in emotion. Personal accomplishment has reduced. However, employees have not felt stressful during contacting with customers. Turnover intention of employees is relatively strong, even a larger proportion of staff make practical plans for their turnover behavior. Moreover, employees with more than three years experience score highest in emotional labor strategy level. That is relevant to the hotel mode: HR would eliminate employees who reach hotel service standards. Secondary highest emotional labor level is new employees whose experience is less than three months. It indicates that new employee tend to work with a relatively high degree of emotion.

\subsection{Implications}

First, add emotional labor appraisal of employees into human resource performance appraisal for hotel corporations, and give real-time monitoring to observe current situation of emotional labor. The ignorance of emotion appliance could be regarded as the error of hotel management. Managerial leaders shouldn't only establish emotional display rules, but also follow the circumstance of rule-execution. In addition, supervision of specific employees who can influence customers' feeling directly would be strengthened.

Next, according to individual factors, the enterprise can train service employees in a different perspective, and then match proper positions with their personality characteristics. The study result above has proved that surface acting level of male employees is significantly higher than female employees'. Increase of surface acting causes the rise of job burnout. Thus hotel managers draft to improve the level of male employees' deep acting, next solve the burnout issue. In the talent recruitment process, it is advisable to arrange employees with more extraversion of personality characteristics to specific positions or departments where need a high level of deep acting.

Finally, pay more attention on recruiting highly educated talents, and look more heavily at employees' diploma. Because higher education leads to more obvious deep acting strategy, whose behavior is that employees objectively regulate their own emotion to satisfy customers' expectation. Doing that can raise customer satisfaction, while reducing emotional exhaustion via producing psychological conflict, so as to reduce turnover rate.

\section{References}

[1] Hochschild, A.R. (1979) Emotion Work: Feeling Rules, and Social Structure. American Journal of Sociology, 85, 555-575. https://doi.org/10.1086/227049

[2] Diefendorff, J.M., Croyle, M.H. and Gosserand, R.H. (2005) The Dimensionality Antecedents of Emotional Labor Strategies. Journal of Vocational Behavior, 66, 
339-357. https://doi.org/10.1016/j.jvb.2004.02.001

[3] Rafaeli, A. and Sutton, R.I. (1987) Expression of Emotion as Part of the Work Role. Academy of Management Review, 12, 23-37.

[4] Pugh, D. (2001) Service with a Smile: Emotional Contagion in Service Encounters. Academy of Management Journal, 44, 1018-1027. https://doi.org/10.2307/3069445

[5] Ashkanasy, N.M., Hartel, C.E.J. and Daus, C.S. (2002) Diversity and Emotion: The New Frontiers in Organizational Behavior Research. Journal of Management, 28, 307-338.

[6] Huang, M.E., Wu, Z.Q. and Tang, G.Q. (2010) How Does Personality Relate to Mental Health in Service Industry Setting? The Mediating Effects of Emotional Labor Strategies. Acta Psychologica Sinica, 42, 1175-1189. https://doi.org/10.3724/SP.J.1041.2010.01175

[7] Yu, Y.P., Luo, J.L. and Wang, P. (2013) Review of Study on Emotional Labor of Lodging Employees. Modernization of Management, No. 3, 98-100.

[8] Zhao, X. (2013) The Research on Relationship of Employees' Emotional Labor, Job Burnout and Turnover Intention in Hotels. Jilin University of Finance and Economics.

[9] Zapf, D. and Holz, M. (2006) On the Positive and Negative Effects of Emotion Work in Organizations. European Journal of Work and organizational Psychology, 15, 1-28. https://doi.org/10.1080/13594320500412199

[10] Johnson, S., Cooper, C., Cartwright, S., Donald, L., Taylor, P. and Millet, C. (2005) The Experience of Work Related Stress across Occupations. Journal of Managerial Psychology, 20, 178-187. https://doi.org/10.1108/02683940510579803

[11] Magdalene, A.C.H. (2012) Emotional Labor and Emotional Exhaustion, Does Co-Worker Support Matter? Journal of Management Research, 12, 115-127.

[12] Dahling, J.J. and Perez, L.A. (2010) Older Worker, Different Actor? Linking Age and Emotional Labor Strategies. Personality and Individual Differences, 48, 574-578.

[13] Grant, A.M. (2013) Rocking the Boat But Keeping It Steady: The Role of Emotion Regulation in Employee Voice. Academy of Management Journal, 56, 1703-1723. https://doi.org/10.5465/amj.2011.0035

[14] Sohn, H.-K. and Lee, T.J. (2012) Relationship between HEXACO Personality Factors and Emotional Labour of Service Providers in the Tourism Industry. Tourism Management, No. 33, 116-125.

[15] Zhang, W., Yan, W. and Tang, S. (2013) Emotional Labor Management in the Tourism Industry Based on HEXACO Theory: Taking the Tourism Industry in Nanjing as a Case. Tourism Forum.

[16] Wang, L., Tang, C. and Gong, S. (2009) The Relationship between Emotional Intelligence, Motivation and Emotional Labor of Service Workers. Economy Management, 31, 86-90.

[17] Lee, D.C. and Hung, L.M. (2012) Does Job Enjoyment and Organizational Support Affect Emotional Labor? Journal of Business Research, 4, 5-29.

[18] Brotheridge, C.M. and Grandey, A.A. (2002) Emotional Labor and Burnout: Comparing Two Perspectives of People Work. Journal of Vocational Behavior, No. 60, 17-39. https://doi.org/10.1006/jvbe.2001.1815

[19] Hochschild, A.R. (1983) The Managed Heart: Commercialization of Human Feeling. University of California Press, Berkeley, Vol. 8, 317-319. 
[20] Whiting, A., Donthu, N. and Baker, A.M. (2011) Investigating the Immediate and Long-Term Effects of Job Stressors on Frontline Service Employees. International Journal of Research in Marketing, 28, 319-331.

[21] Kim, H.J. (2008) Hotel Service Providers' Emotional Labor: The Antecedents and Effects on Burnout. International Journal of Hospitality Management, No. 27, 151-161.

[22] Hülsheger, U.R. and Schewe, A.F. (2011) On the Costs and Benefits of Emotional Labor: A Meta-Analysis of Three Decades of Research. Journal of Occupational Health Psychology, 16, 361-389. https://doi.org/10.1037/a0022876

[23] Kammeyer-Mueller, J.D., Rubenstein, A.L., Long, D.M., et al. (2013) A Meta-Analytic Structural Model of Dispositional Affectivity and Emotional Labor. Personal Psychology, 66, 47-90. https://doi.org/10.1111/peps.12009

[24] Watson, D., Clark, L.A. and Tellegen, A.A. (1988) Development and Validation of Brief Measures of Positive and Negative Affect the PANAS Scales. Journal of Personality \& Social Psychology, 54, 1063-1070.

https://doi.org/10.1037/0022-3514.54.6.1063

[25] Gagne, M. and Forest, J. (2010) The Motivation at Work Scale: Validation Evidence in Two Languages. Educational \& Psychological Measurement, 70, 628-646. https://doi.org/10.1177/0013164409355698

[26] Maslach, C. and Jackson, S.E. (1981) Maslach Burn Inventory-Human Services Survey (HSS). Consulting Psychologists Press, 206-208.

[27] Babakus, E., Yavas, U. and Karatepe, O.M. (2008) The Effects of Job Demands, Job Resources and Intrinsic Motivation on Emotional Exhaustion and Turnover Intentions: A Study in the Turkish Hotel Industry. International Journal of Hospitality \& Tourism Administration, 9, 384-404. https://doi.org/10.1080/15256480802427339 